\title{
If formulation is the heart of cognitive behavioural therapy, does this heart rule the head of CBT therapists?
}

\author{
Michael Zivor $^{1 *}$, Paul M. Salkovskis ${ }^{2}$ and Victoria B. Oldfield ${ }^{3}$ \\ ${ }^{1}$ International Research Collaborative on Anxiety, University of Haifa, Department of Psychology, \\ Mount Carmel, Haifa, Israel \\ ${ }^{2}$ University of Bath, Claverton Down, Bath, UK \\ ${ }^{3}$ Institute of Psychiatry, De Crespigny Park, London, UK
}

Received 10 September 2013; Accepted 20 May 2013

\begin{abstract}
Cognitive behavioural therapy (CBT) is an empirically grounded approach which typically relies on formulation to guide the shape and course of therapy. Cognitive formulation is widely advocated but poorly understood at an empirical level. This study aimed to characterize how clinicians understand the structure and uses of formulation and how they report on using it in their clinical practice relative to an expert reference group. A total of 124 clinicians in routine clinical practice completed a questionnaire, which assessed their clinical use and understanding of formulation. For some aspects of the questionnaire a comparison with a reference group, 15 highly specialist CBT therapists, was used. High levels of self-rated expertise were noted and at levels comparable to that of the highly specialist group. Participants rated themselves as less capable in terms of their formulation skills relative to their self-rating in CBT overall. Formulation is typically rated as important by those with some professional commitment to CBT. There may be some gaps in the way formulation is applied in clinical practice that should be addressed at the level of training and supervision.
\end{abstract}

Key words: CBT, formulation, IAPT, survey, training.

\section{Introduction}

Cognitive behavioural therapy (CBT) evolved from behaviour therapy (Wolpe, 1958) and cognitive therapy (Beck, 1976) and CBT itself has recently come to dominate psychotherapy in countries like the UK, and increasingly worldwide. There has been dismay and puzzlement from those who hold to other 'schools' of psychotherapy - 'why has CBT achieved in a short space of time what other forms of psychotherapy have aspired to but not achieved?' In terms of outcome, other psychological therapies have made (often exaggerated) claims of evidence for effectiveness (Fonagy \& Lemma, 2012; Salkovskis \& Wolpert, 2012) or lack of evidence of ineffectiveness. The answer is in fact more complex than outcome alone, but several of its elements are clear. From the outset (and against considerable opposition)

\footnotetext{
*Author for correspondence: Dr M. Zivor, International Research Collaborative on Anxiety, University of Haifa, Department of Psychology, Mount Carmel, Haifa, 31905, Israel (email: mzivor@gmail.com).
} 
emphasis was placed on gathering and using evidence regarding outcomes (Eysenck, 1952; Wolpe, 1976), embodied in the 'Scientist Practitioner' model (e.g. Barlow, 1981). The clear articulation of empirically validated CBT theory (and the specific application of that theory) and its continuing evolution through experimental validation, allowing extrapolation of both theory and research to novel situations, has led to the framing of CBT as an 'empirically grounded clinical intervention' (Salkovskis, 2002). A key part of this way of implementing treatment and refining its basis both in individual clients seeking to change and in individual treatment and treatment development is the fact that the therapy of scientist practitioners is theory-driven and highly flexible, incorporating a mix of transdiagnostic and problemspecific conceptualizations (e.g. Salkovskis, 1996). Such conceptualizations are shared with the patient through the flexible and client-centred process of formulation which in term forms the basis of a shared understanding, which guides the process of therapy in the hands of capable and interpersonally responsive clinicians.

CBT increasingly faces a new set of challenges; however, with its broad dissemination and rollout in health systems such as the Improving Access to Psychological Therapies (IAPT) programme. The IAPT programme is a UK government initiative aimed at improving access to psychological therapies, which is funded by the Ministry of Health. At the establishment of the IAPT programme, CBT was identified as the preferred choice of treatment for most common mental health problems. The argument for CBT in this context was driven by it being identified as the leading (and in many areas, the only) evidence-based approach to common mental health problems as identified by the UK's National Institute for Health and Clinical Excellence (NICE, 2004a, $b$; 2005). Case formulation (CF) is considered to be at the heart of good CBT and therefore good psychotherapy practice and a key competency in the delivery of good CBT (Beck, 1995; Roth \& Pilling, 2007). However, there are questions about the extent to which formulation-based CBT can survive the 'mass production' of trained therapists involved in its national rollout. Bieling \& Kuyken (2003, p. 53) provide the following definition:

Cognitive case formulation can be defined as a coherent set of explanatory inferences about the factors causing and maintaining a person's presenting problems, inferences derived from the cognitive theory of emotional disorders.

As part of the IAPT programme, a report identifying the 'activities associated with the delivery of high-quality cognitive and behavioural therapy and the competences required to achieve these' was commissioned (Roth \& Pilling, 2007). In this process, CBT treatment manuals were examined in order to identify and assemble therapist competences. This report highlights "the ability to develop formulation and use this to develop treatment plan/case conceptualization' as a specific technique, and a key competency in CBT (Roth \& Pilling, 2007, p. 12). The importance of CBT CF is further reflected in the Cognitive Therapy Scale Revised (CTS-R; Blackburn et al. 2001), through the inclusion of items designed to assess the therapist's use of individualized formulation, namely 'conceptual integration' (Persons \& Bertagnolli, 1999).

There is very little research in this area, in contrast to the more general empirical scrutiny that CBT has undergone in clinical trials. We therefore find ourselves in the unsatisfactory situation where the value of $\mathrm{CF}$ depends on the fact that it is widely regarded as the cornerstone of an evidence-based approach to be utilized by therapists often trained quite differently from those who conducted the treatment trials which should form the focus of therapy used in IAPT and similar programmes. 
Bieling \& Kuyken (2003) devised a set of criteria for evidence-based formulation. This included two categories, i.e. (1) top-down; (2) bottom-up. The top-down category sought to examine whether or not CBT formulation was founded on an evidence-based theory. Following an extensive review of the literature, Kuyken (2006) suggests that there is a large body of research, concerning CBT theories and emotional disorders, providing a 'credible basis for working with clients to develop formulation' (p. 16).

The second category outlined by Bieling \& Kuyken (2003), the bottom-up category, outlined reliability, validity and outcome as criteria for evidence-based formulation. In a test of reliability, research by Persons et al. (1995) set out to test whether 46 clinicians could agree on two aspects of CBT CF, namely (1) the patient's overt problems; and (2) the underlying cognitive mechanisms. The results of this study showed that the clinicians achieved moderate levels of agreement for the overall listing of overt problems, yet lower levels of agreement were achieved for the area of underlying cognitive mechanisms. Kuyken (2006) suggests that poor agreement may be due to heuristic decision-making biases, and suggests that systematic and objective CF systems may be less prone to these biases and that 'true rates of agreement between practitioners should be observable' (p. 23).

Kuyken (2006) suggests that there is a need for research exploring what formulation means to CBT practitioners, what 'form' of formulation they create, and how much their formulation is developed, shared and elaborated during treatment. The current research aims to explore these questions. The primary hypothesis is that in terms of cognitive therapy formulation in the early stages of therapy, clinicians have reasonable levels of knowledge about what is required; matching their own perceived skills, but that clinicians' self-rating of their CF skills may be unrealistically high (Brosan et al. 2008).

\section{Design}

In a cross-sectional design, this study focuses on a description of clinicians' knowledge of, attitudes to, and use of formulation in obsessive compulsive disorder (OCD), using a convenience sample, recruited from participants who signed up for CBT training workshops; this group is described here as the 'clinician group'. Participants completed a questionnaire designed for the purpose of the study. Although the study is descriptive, it was also 'benchmarked' against a small sample of specialist clinicians with known, high levels of training and expertise in CBT formulation in the context of OCD, described here as the "highly specialist (HS) practitioners group', intended as an expert reference group.

\section{Ethical approval}

Ethical approval was received from King's College London Ethical Committee on 10 November 2008.

\section{Participants}

Participants were recruited through advertisements from a total of four workshops. Three of the workshops focused on CBT practice. The fourth workshop, run in collaboration with service users of OCD UK, an OCD charity organization, focused on CBT formulation for OCD. 
Advertisements for the workshops were posted on a range of websites and letters were sent to 250 people who had previously participated in workshops at the Institute of Psychiatry, London.

\section{Inclusion criteria}

The workshops were advertised as suitable for clinicians with all levels of experience, with the purpose of recruiting participants with a broad range of expertise and experience in CBT.

\section{Exclusion criteria}

Individuals with no background as a mental health professional were excluded from the study, as well as those individuals who had been directly involved in the development of the study.

\section{Recruiting the HS group}

In recruiting participants for the HS group, the researcher sent an email detailing the study to the practitioners working at Centre for Anxiety Disorders and Trauma, part of the South London and Maudsley Foundation Trust. Those agreeing to participate were then emailed the relevant research material for the purpose of the comparison. Their responses were then emailed anonymously to the first author.

\section{Measures}

\section{The Professional Training Background and Formulation Questionnaire (PTFQ)}

The main measure was a self-report questionnaire designed specifically for the purpose of the study, i.e. the PTFQ (see Appendix in the Supplementary material). This is a 16-item questionnaire designed for the present study to characterize the participants' clinical use of formulation. The questionnaire is divided into three main sections: (1) Training in CBT (experience and eligibility for accreditation as a CBT practitioner); (2) Clinical use of CBT (time spent discussing it in supervision, tendency to share it with patients); and (3) clinical applications of formulation in CBT (what is important to include in initial formulation). Multiple choice questions and Likert scales were used when appropriate.

The questionnaire had been evaluated for face validity by two independent leading experts in the area of CBT for OCD, namely, Dr Christine Purdon and Dr Adam Radomsky. Face validity was therefore established through expert opinion.

\section{Procedure}

Once consent was obtained, participants attending the workshops completed the questionnaire before the workshop.

\section{Data analysis}

In total, 125 participants completed the PTFQ, two questionnaires were excluded based on lack of adherence criteria. In addition a total of 15 HS practitioners took part in the study. All 
data were managed and analysed using SPSS for Windows, version 16 (SPSS Inc., USA). The alpha value for statistical significance was set at 0.05 .

The main analysis of this study was descriptive, with statistics of central tendency and variance derived for all participants. The comparison with the expert clinician reference group was made using a t test for nominal variables and a $\chi^{2}$ test for categorical variables.

\section{Results}

The clinicians' average years of practising in their core profession since qualifying was 7 years, with a standard deviation of 7.8. Of the sample, the range of experience was from a minimum of no experience at all to a maximum of 30 years.

In terms of competency formulation in CBT, no participant felt extremely competent. However, 52 participants (42.3\%) reported feeling moderately competent to formulate in CBT, while 34 participants $(27.6 \%)$ reported feeling slightly competent with nearly an equal number of participants $(n=30,24.4 \%)$ feeling competent. Only five participants $(4.1 \%)$ did not feel competent at all formulating in CBT (see Table 1 for fuller details). Further demographic data are also shown in Table 1.

\section{Clinical application of CBT}

Overall the responses of the clinicians resembled the HS reference group when asked to rate the importance of including a specific commonly used psychological process in an initial CBT formulation (see Tables 2-4). However, several differences were observed: safety-seeking behaviour was rated as a more important psychological process in formulation by the HS group compared to the clinicians. On the other hand, the psychological processes core beliefs and strengths and protective factors were rated as less important by the HS group relative to the clinicians.

\section{Comparison between the HS group and the clinicians on sharing a formulation}

The majority of clinicians $(n=69,56.1 \%)$ always shared their initial formulation with their patients, while approximately a third of clinicians $(n=37,30.1 \%)$ frequently shared their initial formulation. A minority of clinicians $(n=10,8.1 \%)$ occasionally shared their initial formulation. In addition, only two clinicians (1.6\%) reported never sharing their initial formulation, while one clinician $(0.8 \%)$ reported rarely sharing the initial formulation.

The $\chi^{2}$ analysis suggests that the HS group tend to share their formulation in the first session significantly more that the clinicians who tend to share their formulation in the second session onwards. There were no significant differences in terms of the tendency to reformulate an initial formulation; however, the HS group tended to share their reformulation more frequently than the clinicians.

Comparison between the HS group and the clinicians on the use of formulation as an aid to structure thinking

Overall, there were no significant differences between the clinicians and the HS group in terms of their tendency to use a mental template or a model and to insert information about 
Table 1. Participants' characteristics

\begin{tabular}{|c|c|c|}
\hline Category & Response options & Participants \\
\hline \multirow[t]{10}{*}{ Professional background } & Clinical psychologists & $N=34(34.1 \%)$ \\
\hline & CBT therapists & $26(21.1 \%)$ \\
\hline & Counselling psychologists & $12(9.8 \%)$ \\
\hline & Community psychiatrist nurse & $9(7.3 \%)$ \\
\hline & Mental health workers & $7(5.7 \%)$ \\
\hline & Trainees (psychology) & $9(6.6 \%)$ \\
\hline & Psychiatrist & $5(3.3 \%)$ \\
\hline & Psychotherapist & $9(7.3 \%)$ \\
\hline & Occupational therapist & $1(0.8 \%)$ \\
\hline & Full time & \\
\hline \multirow[t]{7}{*}{ Work setting 1} & Primary care & $54(43.9 \%)$ \\
\hline & Community mental health team & $18(14.6 \%)$ \\
\hline & Secondary care & $17(13.8 \%)$ \\
\hline & Specialist CBT unit & $17(13.8 \%)$ \\
\hline & Tier 3 & $9(7.3 \%)$ \\
\hline & Private practice & $4(3.3 \%)$ \\
\hline & Researcher & $1(0.8 \%)$ \\
\hline \multirow[t]{2}{*}{ Work setting 2} & Adult mental health & $108(87.8 \%)$ \\
\hline & Other & $14(12.2 \%)$ \\
\hline \multirow{4}{*}{$\begin{array}{l}\text { Percentage of time spent in } \\
\text { clinical work }\end{array}$} & $<40 \%$ & $37(30.1 \%)$ \\
\hline & $40-59 \%$ & $36(29.3 \%)$ \\
\hline & $60-79 \%$ & $30(30.4 \%)$ \\
\hline & $80-100 \%$ & $13(10.6 \%)$ \\
\hline \multirow{3}{*}{$\begin{array}{l}\text { Eligibility for accreditation by } \\
\text { BABCP }\end{array}$} & Yes & $42(34.1 \%)$ \\
\hline & No & $76(61.8 \%)$ \\
\hline & Not sure & $5(4.1 \%)$ \\
\hline \multirow{4}{*}{$\begin{array}{l}\text { Perceived level of expertise in } \\
\text { CBT }\end{array}$} & Fairly basic & $14(11 \%)$ \\
\hline & Adequate & $42(34.1 \%)$ \\
\hline & Fairly good & $35(29 \%)$ \\
\hline & Good & $32(26 \%)$ \\
\hline \multirow[t]{6}{*}{ Clinical use of CBT } & Very frequently & $7(5.7 \%)$ \\
\hline & $<20 \%$ of case load & $5(4.1 \%)$ \\
\hline & $20-39 \%$ of case load & $7(5.9 \%)$ \\
\hline & $40-50 \%$ of case load & $15(12.2 \%)$ \\
\hline & $60-79 \%$ of case load & $22(16.9 \%)$ \\
\hline & $80-100 \%$ of case load & $66(53.7 \%)$ \\
\hline \multirow[t]{2}{*}{ Having clinical supervision } & Yes & $110(89.4 \%)$ \\
\hline & No & $11(8.9 \%)$ \\
\hline \multirow{4}{*}{$\begin{array}{l}\text { Time spent in supervision } \\
\text { discussing } \mathrm{CF}\end{array}$} & $<20 \%$ & $30(24.8 \%)$ \\
\hline & $20-39 \%$ & $28(22.8 \%)$ \\
\hline & $40-59 \%$ & $33(26.8 \%)$ \\
\hline & $>60 \%$ & $19(15.5 \%)$ \\
\hline \multirow[t]{5}{*}{ Training in $\mathrm{CF}$} & Extended postgraduate training in CBT & $41(33.3 \%)$ \\
\hline & Participated in workshops which CF was discussed & $42(34.1 \%)$ \\
\hline & Participated in specialized workshops on CF & $28(22.8 \%)$ \\
\hline & $\begin{array}{l}\text { Attended only scientific meetings in which } \mathrm{CF} \\
\text { was discussed }\end{array}$ & $5(4.1 \%)$ \\
\hline & No training at all in $\mathrm{CF}$ & $4(4.3 \%)$ \\
\hline
\end{tabular}

BABCP, British Association for Behavioural and Cognitive Psychotherapies; CF, case formulation. 
Table 2. How important it is to include the following psychological process in an initial CBT formulation [clinicians and highly specialist (HS) group comparison]

\begin{tabular}{|c|c|c|c|c|}
\hline Category & Response options & Clinicians & HS group & $\chi^{2}$ \\
\hline \multirow{2}{*}{$\begin{array}{l}\text { Negative automatic } \\
\text { thoughts/appraisals }\end{array}$} & Very important & $99(81.1 \%)$ & $14(93.3 \%)$ & $\chi^{2}(1)=1.4, p>0.05$ \\
\hline & Important & $23(18.9 \%)$ & $1(6.7 \%)$ & \\
\hline \multirow[t]{3}{*}{ Images } & Very important & $43(35.5 \%)$ & $6(40 \%)$ & $\chi^{2}(2)=5.5, p>0.05$ \\
\hline & Important & $6(5 \%)$ & $3(20 \%)$ & \\
\hline & Moderately important & $72(59.5 \%)$ & $6(40 \%)$ & \\
\hline \multirow[t]{2}{*}{ Mood } & Very important & $93(76.2 \%)$ & $12(80 \%)$ & $\chi^{2}(1)=1, p>0.05$ \\
\hline & Important & $29(23.8 \%)$ & $3(20 \%)$ & \\
\hline \multirow[t]{2}{*}{ Behaviour } & Very important & $102(83.6 \%)$ & $14(93.3 \%)$ & $\chi^{2}(1)=.97, p>0.05$ \\
\hline & Important & $20(16.4 \%)$ & $1(6.7 \%)$ & \\
\hline \multirow[t]{3}{*}{ Physiological reaction } & Very important & $70(57.4 \%)$ & $7(46.7 \%)$ & $\chi^{2}(2)=1.3, p>0.05$ \\
\hline & Important & 39( & $7(46.7 \%)$ & \\
\hline & Moderately important & $13(10.7 \%)$ & $1(4$ & \\
\hline \multirow[t]{3}{*}{ Selective attention } & Very important & $38(31.1 \%)$ & $9(60 \%)$ & $\chi^{2}(2)=5.7, p>0.05$ \\
\hline & Important & $50(41 \%)$ & $5(33.3 \%)$ & \\
\hline & Moderately important & $34(27.9 \%)$ & $1(6.7 \%)$ & \\
\hline \multirow[t]{2}{*}{ Safety-seeking behaviour } & Very important & $79(64.8 \%)$ & $14(93.3 \%)$ & $\chi^{2}(1)=5, p>0.05^{*}$ \\
\hline & Important & $43(35.2 \%)$ & $1(6.7 \%)$ & \\
\hline \multirow[t]{2}{*}{ Triggering event } & Very important & $67(54.9 \%)$ & $6(40 \%)$ & $\chi^{2}(1)=1.1, p>0.05$ \\
\hline & Impo & $.1 \%)$ & $9(60 \%)$ & \\
\hline \multirow[t]{3}{*}{ Conditional assumptions } & Important & $64(54.2 \%)$ & $5(33.3 \%)$ & $\chi^{2}(2)=2.4, p>0.05$ \\
\hline & Moderately important & $40(33.9 \%)$ & $7(46.7 \%)$ & \\
\hline & Of little importance & $14(11.9 \%)$ & $3(20 \%)$ & \\
\hline \multirow[t]{3}{*}{ Core beliefs/schema } & Important & $61(50 \%)$ & $3(20 \%)$ & $\chi^{2}(2)=6.3, p>0.05^{*}$ \\
\hline & Moderately important & $40(32.8 \%)$ & $6(40 \%)$ & \\
\hline & Of little importance & $21(17.2 \%)$ & $6(40 \%)$ & \\
\hline \multirow[t]{2}{*}{ Early life experiences } & Important & $100(83.3 \%)$ & $10(66.7 \%)$ & $\chi^{2}(1)=2.4, p>0.05$ \\
\hline & Of little importance & $20(16.7 \%)$ & $5(33.3 \%)$ & \\
\hline \multirow[t]{3}{*}{ Meta-cognitive beliefs } & Important & $55(45.8 \%)$ & $7(46.7 \%)$ & $\chi^{2}(2)=0, p>0.05$ \\
\hline & Moderately important & $40(33.3 \%)$ & $5(33.3 \%)$ & \\
\hline & Of little importance & $25(20.8 \%)$ & $3(20 \%)$ & \\
\hline \multirow{2}{*}{$\begin{array}{l}\text { Strengths and protective } \\
\text { factors }\end{array}$} & Important & $91(75.2 \%)$ & $2(13.3 \%)$ & $\chi^{2}(1)=23.6, p>0.05^{*}$ \\
\hline & Moderately important & $30(24.8 \%)$ & $13(86.7 \%)$ & \\
\hline
\end{tabular}

* Significant association between group type and rating of a specific psychological process.

Table 3. Sharing a formulation [clinicians and highly specialist (HS) group comparison]

\begin{tabular}{lllll}
\hline Category & Response options & Clinicians & HS group & $\chi^{2}$ \\
\hline If you share, in which session? & 1st & $25(22.1 \%)$ & $10(66.7 \%)$ & $\chi^{2}(1)=13.2, p<0.05^{*}$ \\
& 2nd & $88(77.9 \%)$ & $5(33.3 \%)$ & \\
How often do you modify & Frequently & $89(74.8 \%)$ & $12(80 \%)$ & $\chi^{2}(1)=0.19, p>0.05$ \\
your formulation? & Occasionally & $30(25.2 \%)$ & $3(20 \%)$ & \\
How often do you share & Always & $59(50 \%)$ & $12(80 \%)$ & $\chi^{2}(2)=5.3, p<0.05^{*}$ \\
your re-formulation & Frequently & $42(35.6 \%)$ & $3(20 \%)$ & \\
\hline
\end{tabular}

* Significant association between group type and self-report on sharing a formulation. 
Table 4. To what extent participants use formulation as an aid to structure their thinking [clinicians and highly specialist (HS) group comparison]

\begin{tabular}{|c|c|c|c|c|}
\hline Category & Response options & Clinicians & HS group & $\chi^{2}$ \\
\hline \multirow{2}{*}{$\begin{array}{l}\text { I use a mental template or } \\
\text { model }\end{array}$} & Sometimes & $47(38.8 \%)$ & $5(33.3 \%)$ & \multirow{2}{*}{$\chi^{2}(1)=0.17, p>0.05$} \\
\hline & Very often & $74(61.2 \%)$ & $10(66.7 \%)$ & \\
\hline \multirow{2}{*}{$\begin{array}{l}\text { I like to present a } \\
\text { pre-existing model }\end{array}$} & Never & $17(14.5 \%)$ & $8(53.3 \%)$ & \multirow[t]{2}{*}{$\chi^{2}(1)=13, p<0.05^{*}$} \\
\hline & Rarely & $100(85.5 \%)$ & $7(46.7 \%)$ & \\
\hline \multirow{2}{*}{$\begin{array}{l}\text { I formulate purely on the } \\
\text { basis of what the patient } \\
\text { is telling me which may } \\
\text { or may not fit with a } \\
\text { CBT model }\end{array}$} & Very often & $43(36.1 \%)$ & $10(66.7 \%)$ & \multirow[t]{2}{*}{$\chi^{2}(1)=5.1, p<0.05^{*}$} \\
\hline & Sometimes & $76(63.9 \%)$ & $5(33.3 \%)$ & \\
\hline \multirow{2}{*}{$\begin{array}{l}\text { When a patient present } \\
\text { with comorbid } \\
\text { difficulties, I incorporate } \\
\text { more than one model }\end{array}$} & Sometimes & $97(80.8 \%)$ & $13(86.7 \%)$ & \multirow[t]{2}{*}{$\chi^{2}(1)=0.3, p>0.05$} \\
\hline & Rarely & $23(19.2 \%)$ & $2(13.3 \%)$ & \\
\hline
\end{tabular}

* Significant association between group type and self-report on using formulation as an aid to structure thinking.

a particular patient into the formulation. However, the HS group were less likely to present a pre-existing model of their patient's psychological difficulties compared to the clinicians. In addition, the HS group were more likely to construct a formulation purely on what the patient tells them which may or may not fit with a specific CBT model, in comparison to the clinicians.

\section{Discussion}

The results of the main analysis showed both similarities and differences between clinicians and the HS reference group on their understanding, attitude and reported use of formulation. With regard to the clinicians' view of what is important to include in an initial CBT formulation, differences emerged between the clinicians and the HS group in three out of 13 psychological processes provided, these being: safety-seeking behaviour (this was rated as more important by the HS group) and core beliefs and strengths and protective factors (these were rated as more important by the clinicians).

The analysis suggests that the majority of the clinicians always share their initial formulation with their patients, as is also identified as common practice in the literature. It was further found that the HS group tend to share their formulation in the first session significantly more frequently than the clinicians who tend to share their formulation in the second session onwards. No significant differences in terms of the tendency to reformulate an initial formulation were noted; however, the HS group tended to share their reformulation more frequently than the clinicians group.

Last, there were no differences between the clinicians and the HS group in terms of their tendency to use a mental template or a model and to insert information about a particular patient into the formulation. However, the HS group were less likely to present a 
pre-existing model of their patient's psychological difficulties compared to the clinicians group. In addition, the HS group were more likely to construct a formulation purely on what the patient is telling them, which may or may not fit with a specific CBT model compared to the clinicians group.

It was further noted that in terms of overall perceived competence in the areas of CBT, the findings highlighted that despite clinicians' perceived level of expertise in CBT ranging from adequate to fairly good they had a lower perceived level of competency in formulation in CBT, consistent with the notion that formulation is one of the most complex skills in CBT as stated by Kuyken et al. (2009) and Roth \& Pilling (2007).

The analysis showed that the clinicians group highlighted 'strengths and protective factors' as important processes to be included in an initial formulation. This was, however, less prominent in the HS group. In their model of formulation, Kuyken et al. (2009) highlight these processes as being important. It is notable that the Centre for Anxiety Disorder and Trauma (from where the expert reference group was drawn) emphasizes these processes as a later stage/development of formulation. The questionnaire emphasizes factors involved in initial formulation.

The results suggest that the HS group were more likely to share their reformulation more frequently than the clinicians group. This might indicate that the HS group use a more collaborative/developmental approach to formulation and tend to emphasize the importance of the early development of a shared understanding.

The HS group, as opposed to the clinicians were less likely to use a pre-existing model to guide formulation. This suggests that they take a less 'psychoeducational' and more idiosyncratic approach to formulation. However, the findings further indicate that the HS group are less likely to adhere to a specific prescriptive CBT model, but instead integrate the idiosyncratic experience of the patient with their own expertise in the understanding of anxiety disorders, thus producing a non-standardized model. The advantage of this may be to increase the validity of the formulation in the context of working on a shared understanding of the patient, as demonstrated by Mumma \& Mooney (2007). Nevertheless, it is important that clinicians do not become so focused on idiosyncrasies of formulation that they do not identify factors necessary for translating a formulation into effective treatment.

It is important to note that these findings are far from definitive, but in our view represent a useful starting point for more detailed examination of the way CF is deployed in clinical practice. This was a heterogeneous rather than a representative sample of clinicians working in clinical settings who use CBT on a regular basis. Those who participated were clinicians who typically use CBT as their main psychological approach, attend clinical supervision regularly and work mainly in primary and secondary care. Participants in the expert comparison group work at the Centre for Anxiety Disorder and Trauma and thus their reported use of formulation is most likely influenced by their work setting.

Part of the value of the present study is that it indicates that those who commission and provide CBT training have a means of identifying gaps in expertise, which could be filled by specific skills training sessions and directed supervision to deal with possible shortcomings of training courses involved in the larger scale dissemination of empirically grounded treatments.

The majority of participants in this study did not qualify for British Association for Behavioural and Cognitive Psychotherapies (BABCP) accreditation. Future research could examine the formulation practice of accredited clinicians, comparing the results to those of the present study. 


\section{Supplementary material}

For supplementary material accompanying this paper visit http://dx.doi.org/10.1017/ S1754470X1300010X.

\section{Declaration of Interest}

None.

\section{References}

Barlow DH (1981). On the relation of clinical research to clinical practice: current issues, new directions. Journal of Consulting and Clinical Psychology 49, 147-155.

Beck AT (1976). Cognitive Therapy and the Emotional Disorder. New York: Meridian.

Beck JS (1995). Cognitive Therapy: Basics and Beyond. New York: Guilford Press.

Bieling PJ, Kuyken W (2003). Cognitive case formulation: science or science fiction? Clinical Psychology: Science and Practice 10, 52-69.

Blackburn IM, James IA, Milne DL, Baker C, Standart S, Garland A, Reichelt KF (2001). The Revised Cognitive Therapy Scale (CTS-R): psychometric properties. Behavioural and Cognitive Psychotherapy 29, 431-446.

Brosan L, Moore R, Reynolds S (2008). Self evaluation of cognitive therapy performance: Do therapists know how competent they are? Behavioural and Cognitive Psychotherapy 36, 581-587.

Eysenck HJ (1952). Effects of psychotherapy: an evaluation. Journal of Consulting Psychology 16, 319-324.

Fonagy P, Lemma A (2012). Does psychoanalysis have a valuable place in modern mental health services? Yes. British Medical Journal 344, e1211.

Kuyken W (2006). Evidence-based case formulation: is the emperor clothed? In: Case Formulation in Cognitive Behaviour Therapy (ed. N. Tarrier), pp. 12-36. Hove, UK: Brunner-Routledge.

Kuyken W, Padesky CA, Dudley R (2009). Collaborative Case Conceptualization. London: Guilford Press.

Mumma GH, Mooney SR (2007). Comparing the validity of alternative cognitive case formulations: a latent variable, multivariate time series approach. Cognitive Therapy and Research 31, 451-481.

NICE (2004a). Depression: management of depression in primary and secondary care (http://www. nice/org.uk/pdf.CG023NICEguideline.pdf). National Institute for Clinical Excellence.

NICE (2004b). Anxiety: management of anxiety (panic disorder, with or without agoraphobia, and generalized anxiety disorder) in adults in primary secondary and community care (http://www.nice. org.uk/pdf/CG022NICEguideline.pdf). National Institute for Clinical Excellence.

NICE (2005). Obsessive-compulsive disorder: core interventions in the treatment of obsessivecompulsive disorder and body dysmorphic disorders. Clinical Guidelines (http://www.nice.org.uk/ nicemedia/pdf/cg031fullguideline.pdf). National Institute for Clinical Excellence.

Persons JB, Bertagnolli A (1999). Inter-rater reliability of cognitive-behavioral case formulations of depression: a replication. Cognitive Therapy and Research 23, 271-283.

Persons JB, Mooney KA, Padesky CA (1995). Interrater reliability of cognitive-behavioral case formulations. Cognitive Therapy and Research 19, 21-34.

Roth AD, Pilling S (2007). Competencies required to deliver effective cognitive and behavior therapy for people with depression and with anxiety disorders. London: HMSO, Department of Health.

Salkovskis PM (1996). Trends in Cognitive and Behavioural Therapies. Chichester: J. Wiley \& Sons.

Salkovskis PM (2002). Empirically grounded clinical interventions: cognitive-behavioural therapy progresses through a multi-dimensional approach to clinical science. Behavioural and Cognitive Psychotherapy 30, 3-9. 
Salkovskis PM, Wolpert L (2012). Does psychoanalysis have a valuable place in modern mental health services? No. British Medical Journal 344, e1188.

Wolpe J (1958). Psychotherapy via Reciprocal Inhibition. Stanford, CA: Stanford University Press.

Wolpe J (1976). Behavior therapy and its malcontents - I: Denial of its basis and psychodynamic fusionism. Journal of Behavior Therapy and Experimental Psychiatry 7, 1-5.

\section{Learning objectives}

(1) To find out how a group of clinicians perceive their formulation skills.

(2) To identify gaps in CBT knowledge and expertise.

(3) To learn if and how CBT practitioners use formulation in their clinical setting.

(4) To identify possible differences between clinicians and highly specialist clinicians in their use of formulation in CBT practice? 